\title{
Status Epilepticus in Children
}

\author{
Col M K Behera*, Lt Col K S Rana ${ }^{+}$, Lt Col M Kanitkar ${ }^{\#, ~ S u r g ~ C d r ~ K ~ M ~ A d h i k a r i * * ~}$
}

\begin{abstract}
Status epilepticus (SE) is a life-threatening emergency that requires prompt treatment, including basic neuroresuscitation principles (the $\mathrm{ABCs}$ ), antiepileptic drugs to stop the seizure and identification of etiology. It results from an inability to normally abort an isolated seizure either due to ineffective inhibition, or due to abnormally persistent excessive excitation. Symptomatic $\mathrm{SE}$ is more common in younger children and the likely etiology depends on the age of the child. Treating the precipitating cause may prevent ongoing neurologic injury and facilitates seizure control. Benzodiapenes, phenytoin and phenobarbital form the mainstay of treatment. A systematic treatment regimen, planned in advance, is needed, including one for refractory status epilepticus (RSE). Patient education and home management of seizures is important to reduce the morbidity and mortality associated with SE.
\end{abstract}

MJAFI 2005; $61: 174-178$

Key Words : Seizures; Children; Management

\section{Introduction}

S tatus epilepticus is a common pediatric neurological emergency that requires immediate and vigorous management and at times poses a therapeutic challenge to the treating physician. If not managed promptly, it may result in significant neuromorbidity and mortality $[1,2]$.

In 1981, the International League Against Epilepsy defined SE as a single seizure or recurrent seizures lasting for more than 30 minutes during which consciousness is not regained [3]. However it is now being recognized that even a 10 minute seizure activity can lead to brain damage; hence the duration of a seizure required to define SE is being reduced [4]. Practically most seizures resolve within few minutes, so seizures persisting longer than 5 minutes should probably be treated as SE.

\section{Incidence}

It is estimated that 1.3 to $16 \%$ of all patients with epilepsy will develop SE at some point in their lives [2]. Approximately $70 \%$ of SE occurs in children less than one year and $75 \%$ in less than three years of age [5] and the first episode most commonly occurs around 2.5 years after initial diagnosis [6]. It has been observed that $20 \%$ of individuals with epilepsy will have an episode of SE within 5 years of the initial diagnosis [7]. SE before initial diagnosis of epilepsy, young age at onset and symptomatic etiology independently influence the risk of subsequent episodes of SE.

\section{Classification and Etiology}

SE can be classified as generalized, partial, nonconvulsive and neonatal (Table 1). Generalized tonic clonic status is the most common form and carries the highest mortality and morbidity. It can also be differentiated on the basis of the underlying cause. A primary central nervous system (CNS) disorder or a metabolic abnormality may result in an episode of SE. Some such important conditions are trauma, infections such as meningitis or encephalitis, hypoxic-ischaemic

Table 1

Clinical classification of SE

- Generalized convulsive SE [GCSE]

Primary generalized

Tonic-clonic

Myoclonic

Clonic/Tonic

- Secondary generalized SE

Partial seizures with secondary generalization

Tonic Seizures

- Non-convulsive SE [NCSE]

Absence status [Petit Mal]

Atypical absence status

Atonic

NCSE due to partially treated GCSE

- Partial SE

Simple partial

Typical

Epilepsia partialis continua

Complex partial SE [CPSE]

- Neonatal SE 
encephalopathy, intra-cranial tumors and cerebrovascular diseases. It has been observed that the classical symptoms and signs of acute bacterial meningitis may be absent in SE and a high index of suspicion for infection in the child with SE and fever is paramount [8]. Metabolic abnormalities such as hypoglycemia, hyperglycemia, hyponatremia, hypernatremia, hypomagnesaemia, hypocalcaemia and uremia may precipitate an episode of SE. Systemic disorders like hypertension may occasionally present with SE. Non-compliance with antiepileptic medications, abrupt drug withdrawal or even drug over dosage can result in SE.

The most important cause for SE varies with the age of the child. Whereas febrile SE is the most common cause in children less than five years of age, trauma and infections are important in older children [1]. Severe hypoxic encephalopathy and inborn error of metabolism may present with SE in the newborn $[9,10]$.

The important risk factors for SE are a history of epilepsy, younger age of patient, genetic predisposition and acquired brain insult [11]. The important precipitating factors include fever, irregular or overdose of antiepileptic drug (AED) medications, sudden discontinuation of AED, sleep deprivation, fatigue, metabolic derangements, concomitant use of other medications (theophyline, amphitamine, isoniazid) hyperventilation and intermittent photic stimulation.

\section{Pathophysiology}

Status epilepticus results from an inability to normally abort an isolated seizure either due to ineffective inhibition, or due to abnormally persistent excessive excitation. Excessive activation of excitatory amino acid receptors or an excessive release of glutamate can cause prolonged seizures. Drugs and compounds that antagonize the effects of G-amnio-butyric acid (GABA) which is the main inhibitory neurotransmitter of the brain, may cause SE [12]. The most vulnerable areas include the limbic system, cerebellum, middle cortical area and the thalamus.

At the cellular level, ischemic cellular changes due to an increase in metabolic demand, depletion of glucose stores and oxygen supply are the earliest histologic findings. This is followed by neuronophagia, microglial and astrocyte proliferation and cell loss. Prolonged seizure activity results in hypotension, hyperkalemia, hypoglycemia, lactic acidosis, myoglobinuria, acute tubular necrosis and death. Early termination of the seizure activity and meticulous supportive care can circumvent most of the deleterious effects of SE and limit the morbidity and mortality.

\section{Management}

Managing a child with SE is a continuous process of evaluation and treatment being carried out simultaneously. As in any emergency, "ABC" for life support takes priority. The airway is assessed and secured. The child positioned properly to avoid aspiration and physical injury, an oral or nasopharyngeal air way used to maintain patency if required and oxygen administered by a nasal cannula or mask. Use of tongue blades or other metallic objects is avoided to prevent oral injury. Excessive secretions are removed by gentle suction and endotracheal intubation is considered in an unstable airway. Nasogastric tube is used to empty the stomach and may be left in situ. It is preferable to insert two intravenous catheters for fluid therapy, medications and collection of blood samples as depicted in Table 2 . Thereafter medications are administered to control seizures at the earliest. Lumbar puncture and all other investigations are performed only after achieving control of seizures and excluding raised intracranial tension by means of a fundoscopic examination.

\begin{tabular}{|c|c|}
\hline Specimen & Investigation \\
\hline - Blood & $\begin{array}{l}\text { Complete blood count } \\
\text { Electrolytes } \\
\text { Glucose, } \\
\text { Calcium, Magnesium, } \\
\text { Creatinine, Liver function test, } \\
\text { Lactate, Arterial blood gas analysis } \\
\text { Anticonvulsant levels }\end{array}$ \\
\hline - $\mathrm{CSF}$ & $\begin{array}{l}\text { Biochemistry } \\
\text { Cytology } \\
\text { Bacteriology, viral studies }\end{array}$ \\
\hline $\begin{array}{l}\text { - Urine } \\
\text { - } \mathrm{CT} \mathrm{Scan/MRI} \mathrm{Brain} \\
\text { - } \text { EEG }\end{array}$ & Routine, microscopy, myoglobin \\
\hline
\end{tabular}

The main aim of initial management is the maintenance of vital parameters, adequate brain oxygenation and termination of seizure activity as early as possible in a systematic manner. Medications used for seizure control are discussed subsequently. If hypoglycemia is detected or a blood glucose determination is not available, a rapid infusion of $25 \%-10 \%$ glucose in a dose of $2-5 \mathrm{ml}$ per $\mathrm{kg}$ body weight is administered intravenously [13]. Thereafter maintenance intravenous fluid is given preferably as half strength normal saline in 5\% dextrose, normal saline, or ringer's lactate. Fluid intake should be restricted if the child develops features of Syndrome of Inappropriate Antidiuretic Hormone Secretion (SIADH) in the form of edema, hyponatremia and reduced serum osmolality. Blood pressure of the child should be maintained at levels appropriate for the age of the child. 
The temperature is monitored and hyperthermia treated promptly.

A quick history and physical examination including neurological assessment should be done concurrently to detect evidence of trauma, raised intracranial pressure (papilledema, bulging anterior fontanel or focal neurological signs) and features of sepsis or meningitis. Retinal hemorrhages, irregular respiration and pupillary size abnormalities may indicate a subdural hematoma, brainstem dysfunction or ingestion of a toxin respectively. Further investigations can be planned after a detailed history and systemic examination. Long term management includes prevention of recurrence of seizures, identification of precipitating factors, correction of metabolic disturbances, prevention of systemic complications and management of the underlying cause.

\section{Control of seizures}

More than half of the patients with SE will respond to therapy with a single anti epileptic drug. Drugs should always be administered intravenously. In case of a difficult access, per rectal diazepam, lorazepam, valproate or paraldehyde may be used. Midazolam can be given intranasal or intramuscular. Lorazepam may be given sublingual. An ideal anti epileptic for SE should have following properties; rapid onset of action, wide spectrum of activity, intravenous preparation, ease of administration, minimal redistribution from the CNS, short elimination half-life and a wide therapeutic safety margin.

Benzodiazepines These drugs act as agonists at GABA receptors and potentiate inhibition of neuronal firing. They are potent and fast acting drugs which are used as the initial therapy. Lorazepam is being preferred as the drug of choice for initial therapy. The dose is $0.05-0.1 \mathrm{mg} / \mathrm{kg}$ intravenous. Mean time for seizure cessation is 3 minutes. Duration of antiseizure effect is 12-24 hours. If lorazepam is not available, diazepam a short-acting but effective drug is administered. It should be followed within 20 minutes by a long acting drug such as phenytoin. It should be given directly into the vein. The dose is $0.1-0.3 \mathrm{mg} / \mathrm{kg}$ at rate not greater than $2 \mathrm{mg} / \mathrm{min}$ for a maximum of 2 doses. Midazolam may also be used as the initial drug. The dose is 0.1 to 0.2 $\mathrm{mg} / \mathrm{kg}$ to a maximum of $5 \mathrm{mg}$. It can be administered by the intravenous, intranasal, buccal, rectal or intra muscular routes. But its use as first line drug in the treatment of SE is not widely accepted. Its potent anti epileptic effect, relative safety record, and ease of administration by various routes clearly makes midazolam a potentially important and useful drug in the treatment of SE inside and outside of the hospital. Its optimal dosing, safety and clinical usefulness in various settings needs further evaluation.

Adverse effects of benzodiazepines include respiratory depression, hypotension and impaired consciousness. Contrary to the Advanced Pediatric Life Support guidelines many children admitted for SE receive over two doses, or inadequate doses of benzodiazepine [10].

Phenytoin and Fosphenytoin These drugs are longacting anticonvulsants that act by stabilizing the neuronal membrane. Phenytoin remains the drug of choice for second-line therapy in SE that does not respond to lorazepam or diazepam and is also used for maintaining anti seizure effect after the initial therapy with diazepam. A loading dose of $20 \mathrm{mg} / \mathrm{kg}$ is infused slowly after diluting with saline at a maximum rate of $1 \mathrm{mg} / \mathrm{kg} / \mathrm{min}$ in children. It is advisable to avoid dextrose-containing solutions as diluents to prevent precipitation. ECG and blood pressure monitoring is recommended as the drug can cause arrhythmias and hypotension. The infusion can be repeated in a dose of $5 \mathrm{mg} / \mathrm{kg}$. As much as 30 $\mathrm{mg} / \mathrm{kg}$ may be required to stop seizures in some patients. Therapeutic serum concentration is attained within 10 minutes. It is highly lipid soluble and reaches peak brain levels within 15 minutes after intravenous administration. Maintenance dose of $5-8 \mathrm{mg} / \mathrm{kg} /$ day can be given in two divided doses after 12-24 hours of initial loading dose and seizure control.

Fosphenytoin is a prodrug of phenytoin. It is watersoluble, causes less infusion site reactions and carries a smaller risk for hypotension. The dose is in phenytoin equivalents (PE). It can be given at a rate of $3 \mathrm{mg} / \mathrm{kg} /$ min. This drug can also be administered as an intramuscular injection.

Phenobarbital This long-acting potent anti epileptic drug is used when benzodiazepines and phenytoin are ineffective to control seizures. It is given as a loading dose of $15-20 \mathrm{mg} / \mathrm{kg}$ over $10-30 \mathrm{~min}$, the rate not exceeding $30 \mathrm{mg} / \mathrm{min}$. The bolus is repeated at the rate of $10 \mathrm{mg} / \mathrm{kg}$ every 30 minutes until seizure control is achieved. Doses as high as $120 \mathrm{mg} / \mathrm{kg}$ have been used in Refractory Status Epilepticus (RSE). The maintenance dose is $3-5 \mathrm{mg} / \mathrm{kg} /$ day, given as two divided doses, 12-24 hours later. The drug may depress respiration and level of consciousness, especially if benzodiazepines have also been given.

Paraldehyde This drug is relatively safe for administration in children, however presently it is not used very often due to the availability of better drugs. The per rectal dose of paraldehyde is $0.3-0.5 \mathrm{ml} / \mathrm{kg}$ to a maximum of $5 \mathrm{ml}$, diluted $1: 1$ in vegetable oil. This dose can be repeated at 20 minute intervals if seizures persist [9]. 
Valproic Acid Intravenous valproic acid has been recently introduced in the market and is found to be effective in controlling SE. The dose is $25 \mathrm{mg} / \mathrm{kg}$ (3 $\mathrm{mg} / \mathrm{kg} / \mathrm{hr}$ ). Per rectal sodium valproate can be given as a retention enema in a dose of $20 \mathrm{mg} / \mathrm{kg}$.

\section{Refractory Status Epilepticus (RSE)}

The definition of RSE includes seizures that have not responded to sequential treatment of lorazepam, phenytoin and phenobarbitone or a seizure continuing for over sixty minutes in spite of adequate treatment. This is an emergency and its management is depicted in Fig 1. Intravenous infusions of midazolam, propofol or barbiturates are considered. Patient should be managed in an intensive care unit where facilities for monitoring and ventilatory support are available. Midazolam infusion $0.15 \mathrm{mg} / \mathrm{kg}$ bolus is followed by an infusion of $1 \mathrm{~g} / \mathrm{kg} /$ min every 15 minutes till seizure control is achieved or maximum dose of $18 \mathrm{~g} / \mathrm{kg} / \mathrm{min}$ is reached. The infusion should be maintained for twelve hours after the last seizure and then gradually tapered off. ECG and blood pressure monitoring are necessary and when possible an EEG monitoring is recommended. Complete control of seizures with midazolam infusion can be achieved in over $90 \%$ of children within an hour; at a mean infusion rate of $3 \mathrm{mg} / \mathrm{kg} / \mathrm{min}$. Adverse effects such as hypotension, bradycardia or respiratory depression are unlikely to occur during midazolam infusion [14]. If midazolam is not available, diazepam can be used. Diazepam infusion is effective if the patient had an initial response to the drug and should be used when ventilatory support is readily available. It is diluted with normal saline, ringer lactate or dextrose, to a dilution of $0.04 \mathrm{mg} / \mathrm{ml}$. The infusion is given in a dose of $0.01 \mathrm{mg} / \mathrm{kg} / \mathrm{min}$ and

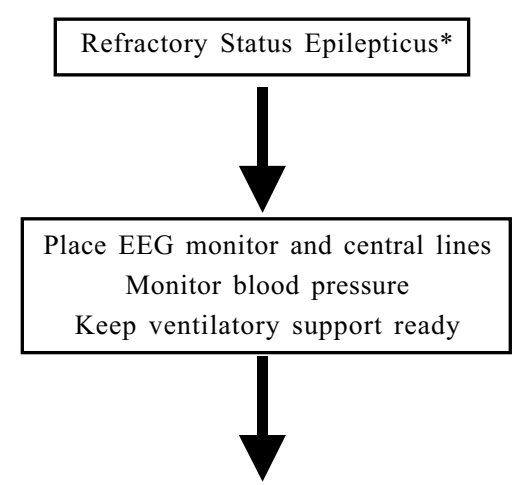

Midazolam $0.15 \mathrm{mg} / \mathrm{kg}$ stat, infusion $0.75-18 \mathrm{ug} / \mathrm{kg} / \mathrm{minute}$ or Diazepam $0.3 \mathrm{mg} / \mathrm{kg}$ stat, infusion $0.01-0.04 \mathrm{mg} / \mathrm{kg} / \mathrm{min}$ or With ventilatory support

Propofol $1-3 \mathrm{mg} / \mathrm{kg}$ stat, infusion $2-10 \mathrm{mg} / \mathrm{kg} / \mathrm{hr}$ or Pentobarbital $5-15 \mathrm{mg} / \mathrm{kg}$ stat, infusion $0.5-5 \mathrm{mg} / \mathrm{kg} / \mathrm{hr}$ or Thiopental infusion $3-4 \mathrm{mg} / \mathrm{kg}$ stat, infusion $1-10 \mathrm{mg} / \mathrm{kg} / \mathrm{min}$

*Best managed in the pediatric intensive care unit

Fig. 1 : Management of refractory status epilepticus gradually increased every five minutes till seizures are controlled or a maximum dose of $0.04 \mathrm{mg} / \mathrm{kg} / \mathrm{min}$ is reached. Intravenous valproic acid has also been used in RSE in a loading dose of $20-40 \mathrm{mg} / \mathrm{kg}$-diluted $1: 1$ in normal saline or $5 \%$ dextrose administered over five minutes. This is repeated after 10-15 minutes if required, followed by an infusion of $5 \mathrm{mg} / \mathrm{kg} / \mathrm{hr}$. Propofol has gained popularity as an alternative highly effective, nonbarbiturate, anesthetic agent with barbiturate and benzodiazepine-like effects at the GABA receptor. It has a potent anticonvulsant action in clinical doses of 1$3 \mathrm{mg} / \mathrm{kg}$ given intravenous followed by continuous infusion of $2-10 \mathrm{mg} / \mathrm{kg} / \mathrm{h}$. Cessation of seizure activity occurs within few seconds. Adverse effects include bradycardia, apnea, hypotension and it can itself cause seizures or unexplained metabolic acidosis. Endotracheal intubation and mechanical ventilation is almost invariably necessary. Serious doubts are being raised on the safety of propofol in the treatment of RSE. Several case reports show an increased risk of mortality [15]. Guidelines should not recommend the use of propofol as a routine treatment in RSE before a proper randomised trial has been performed. All prior anticonvulsants administered should be continued and maintained at therapeutic levels while treating RSE. Other drugs used in RSE include lidocaine, clonazepam and chlormethiazole. Small children may be given mega doses of multivitamin, especially $\mathrm{B}_{1}, \mathrm{~B}_{2}, \mathrm{~B}_{12}$ and Biotin. Pyridoxine dependent seizures are not uncommon in infants. Factors responsible for refractory seizures include inadequate drug doses, improper route of administration and metabolic derangements.

General Anesthesia If conventional drug therapy fails to control seizures; general anesthesia can be used as adjunct in the management of SE. Thiopental is a short acting general anesthetic. The dose is $3-4 \mathrm{mg} / \mathrm{kg}$ IV over 2 minutes followed by continuous infusion of $0.2 \mathrm{mg} / \mathrm{kg} / \mathrm{min}$. The rate can be increased by $0.1 \mathrm{mg} /$ $\mathrm{kg} / \mathrm{min}$ every 3-5 minutes till the SE is controlled. Continuous EEG monitoring is recommended. Other anaesthetic agents used include pentobarbitone sodium, isoflurane, etomidate and ketamine infusion

\section{Home management}

Status epilepticus frequently occurs outside the hospital. Rectal, intranasal, buccal and sublingual routes of drug administration may be used. Midazolam can be given intranasally $(0.2 \mathrm{mg} / \mathrm{kg})$ and bucally $(0.3 \mathrm{mg} / \mathrm{kg})$. Rectal administration of diazepam $0.5-1 \mathrm{mg} / \mathrm{kg}$ to a maximum of $10 \mathrm{mg}$ or lorazepam $0.1-0.4 \mathrm{mg} / \mathrm{kg}$ is safe. For most children at highest risk, maintaining abortive therapy in the home may be a reasonable precaution. It is observed that more than half of the patients with SE do not receive their first antiepilepsy drug within 30 
minutes [16]. Thus there is a need for patient education regarding seizure emergencies and wider availability of at-home treatment options to shorten time to seizure treatment in patients at risk.

\section{Prognosis}

The prognosis and outcome SE depends upon etiology and duration of seizures, associated systemic abnormalities, age of the patient, and the type of treatment. The initial mortality rate was reported to be between 6 to $30 \%[9,13]$. Despite recent improvements in diagnosis and therapeutic management, SE is still associated with significant mortality, with a case fatality reaching $3-10 \%$ [17]. Early patient management could influence the outcome of SE. Long-term sequelae include epilepsy in $20-40 \%$, encephalopathy in $6-15 \%$ and focal neurological deficits in $9-11 \%$. RSE may occur in $26 \%$ of children with SE [18].

\section{Conclusion}

Status epilepticus is a pediatric medical emergency requiring prompt intervention. The mortality and morbidity associated with SE has decreased over the years due to a systematic approach and prompt management. Acute central nervous injury continues to contribute significantly to the mortality rate.

Children actively convulsing on arrival to the emergency department should be assumed to be convulsing for at least 10 minutes and treated accordingly. First-line of drugs like benzodiazepines, phenytoin and phenobarbitone usally control the SE in such cases. RSE should be managed in the pediatric intensive care unit with the facilities of ventilatory support. It necessitates use of midazolam, pentobarbital, or propofol. The use of rectal, intranasal or buccal routes may circumvent vascular access problems in children. Prevention of status is equally important. Promotion of domiciliary management will contribute towards decreasing the burden of SE.

\section{References}

1. Singhi S, Singhi P, Dass R.: Status epilepticus : Emergency management. Indian J Paediatric 2003; 70 (Special suppl 1) S1-22.

2. Hanhan UA, Fiallos MK, Orlowski JP. Status epilepticus. Pediatr Clin North Am 2001;48:683- 94.
3. Working Group on Status epilepticus. Treatment of convulsive status epilepticus. Recommendations of the epilepsy foundation of America's working Group on SE. JAMA 1993;270:854-9.

4. Riviello JJ Jr, Holmes GL. The treatment of Status epilepticus. Semin Pediatr Neurol 2004;11:129-38.

5. Tullu MS, Mukhija V. Status epilepticus. In: Suraj Gupte, editor. Recent Advances in Pediatrics. Special Volume 14. New Delhi: Jaypee Brothers 2004;15-31.

6. Berg AT, Shinnar S, Testa FM, Levy SR, Frobish D, Smith SN, et al. Status epilepticus after the initial diagnosis of epilepsy in children Neurology 2004;63;1027-34.

7. Segeleon JE, Haun SE. Status epilepticus. In: Tobias JD, editors. Pediatric Critical Care: The Essentials. Chennai: Orient Longman 2000:207-21.

8. Chin RF, Neville BG, Scott RC. Meningitis is a common cause of convulsive status epilepticus with fever. Arch Dis Child 2005;90:66-9.

9. Gulati S, Vasudevan A. Status epilepticus. In: Suraj Gupte, editor. Text Book of Pediatric Emergencies. New Delhi: Peepee Publishers and Distributors 2004;134-41.

10. Chin RF, Verhulst L, Neville BG, Peters MJ, Scott RC. Inappropriate emergency management of Status epilepticus in children contributes a need for intensive care. J Neurol Neurosurg Psychiatry 2004;75:1584-8.

11. Fountain NV. Status epilepticus: Risk factors and complications. Epilepsia 2000;41[Suppl 2]:23-30.

12. Scott RC, Surtees RAH, Neville BGR. Status epilepticus: Pathophysiology, epidemiology and outcomes. Arch Dis Child 1998;79:73-7.

13. Tasker RC. The management of acute epileptic seizures and status epilepticus. In: David TJ editor. Recent Advances in Pediatrics. Volume19. London: Churchill Livingstone 2001:116.

14. Ozdemir D, Gulez P, Uran N, Yendur G, Kavakli T, Aydin A. Efficacy of continuous midazolam infusion and mortality in childhood refractory generalized convulsive status epilepticus. Seizure 2005; 14:129-32.

15. Niermeijer JM, Uiterwaal CS, Van Donselaar CA. Propofol in status epilepticus: Little evidence, many dangers? J Neurol 2003;250:1237-40

16. Pellock JM, Marmarou A, DeLorenzo R. Time to treatment in prolonged seizure episodes. Epilepsy Behav 2004;5:192-6.

17. Jallon P. Mortality in patients with epilepsy. Curr Opin Neurol 2004;17:141-6.

18. Maytal J, Shinnar S, Moshe SL, et al. Low morbidity and mortality of status epilepticus in children. Pediatrics 1989;83:323-31. 